\title{
Magnetic Resonance Spectroscopy and Prognostic Analysis of Molecular Subtypes of Medulloblastoma
}

\author{
Yuting Zhang1, Lusheng $\mathrm{Li}^{2,3,4,5,6^{*}}$ \\ ${ }^{1}$ Department of Radiology, Children's Hospital of Chongqing Medical University, Chongqing, China \\ ${ }^{2}$ Department of Neurosurgery, Children's Hospital of Chongqing Medical University, Chongqing, China \\ ${ }^{3}$ Ministry of Education Key Laboratory of Child Development and Disorders, Chongqing, China \\ ${ }^{4}$ National Clinical Research Center for Child Health and Disorders, Chongqing, China \\ ${ }^{5}$ Chongqing Key Laboratory of Pediatrics, Chongqing, China \\ ${ }^{6}$ China International Science and Technology Cooperation Base of Child Development and Critical Disorders, Chongqing, China \\ Email: *lilusheng@cqmu.edu.cn
}

How to cite this paper: Zhang, Y.T. and Li, L.S. (2020) Magnetic Resonance Spectroscopy and Prognostic Analysis of Molecular Subtypes of Medulloblastoma. Open Journal of Clinical Diagnostics, 10, 81-91. https://doi.org/10.4236/ojcd.2020.103007

Received: June 20, 2020

Accepted: September 22, 2020

Published: September 25, 2020

Copyright (c) 2020 by author(s) and Scientific Research Publishing Inc. This work is licensed under the Creative Commons Attribution International License (CC BY 4.0).

http://creativecommons.org/licenses/by/4.0/

(c) (i) Open Access

\begin{abstract}
Aim: The aim of this study was to investigate whether magnetic resonance spectrum (MRS) and MR imaging features can be used for non-invasive medulloblastoma subgrouping, and analyse patient characteristics and prognosis of molecular subtypes of medulloblastoma. Material and Methods: 32 patients with medulloblastoma underwent MRI prior to surgical resection, 16 of them underwent MRS. MR imaging features and metabolites measured by MRS were analysed to distinguish molecular subtypes of medulloblastoma. Patient demographics, histopathological types, and prognosis of different molecular subtypes were analysed and compared respectively. Results: MRS and MR imaging features differed from different individuals, but without statistical significance that involves acquiring non-quantitative $\mathrm{MR}$ imaging features and NAA/Cr, Cho/Cr, $\mathrm{Lip} / \mathrm{Cr}$, Glu and Gln/Cr ratio, to be used to determine molecular subtypes. There was no significant difference of the three molecular subtypes in age, gender and pathological type. The 5-year event-free survival (EFS) of SHH, WNT and non SHH/WNT subtype respectively were $75 \%, 57.1 \%, 38.1 \%$, with no significant difference $(p=0.382)$. 5 -year EFS of non SHH/WNT subtype was significantly higher in $\leq 3$ years old group than $>3$ years old group $(p=0.047)$. Conclusion: MRS and MR imaging features can't be used to determine molecular subtypes based on our small sample study. There was no significant difference of the prognosis in the three molecular subtypes. The prognosis of $\leq 3$ years old group of non $\mathrm{SHH} / \mathrm{WNT}$ subtype is better than $>3$ years old group.
\end{abstract}




\section{Keywords}

Medulloblastoma, Molecular Subtypes, MRS, 5-Year EFS

\section{Introduction}

Medulloblastoma is an invasive embryonal tumor of central nervous system, accounting for about $20 \%$ of intracranial tumors and $40 \%$ of tumors in the posterior fossa in children, in addition to pilocytic astrocytoma it was another kind of high incidence posterior fossa tumors in children [1]. Studies had shown that age, gender, location, tumor resection degree, proliferation index and histopathological types would not affect the prognosis of medulloblastoma [2] [3]. In recent years, the research progress of molecular biology showed that the prognosis of medulloblastoma had close correlation with molecular subtypes [4] [5] [6]. Medulloblastoma can be divided into four subtypes according to the genomic characterization: wingless (WNT), sonic hedgehog (SHH), group 3 and group 4 that combined to non SHH/WNT [7] [8].

The in vivo and non-invasive biomarkers to molecular subtypes of medulloblastoma could facilitate the treatment strategies of these tumors in children. Magnetic resonance spectrum (MRS) has great significance in the differential diagnosis of brain tumors and predicting the clinical outcomes, which determines in vivo concentrations of metabolites of the tumors [9] [10]. Blüml S et al. [11] reported MRS as a non-invasive and accurate tool to differentiate molecular subtypes of medulloblastoma. Peet AC et al. [12] reported MRS could suggest key differences in the metastatic behaviour of medulloblastoma.

In this study we acquired metabolites measured by MRS of 16 patients and MR imaging features of 32 patients with medulloblastoma, to investigate their prediction of molecular subtypes of pediatric medulloblastoma. Furthermore, we analysed patient demographics, histopathological types, and prognosis of molecular subtypes of medulloblastoma.

\section{Materials and Methods}

\subsection{Patients}

32 patients with medulloblastoma underwent MRI prior to surgical resection and 16 of them underwent MRS at our hospital from January 2010 to December 2013. Our institution's Committee on Clinical Research Ethics approved the study protocol, and informed consent was obtained from the parents. The eligibility criteria including: 1) less than 16 years old; 2) postoperative pathology confirmed medulloblastoma; 3) Standard chemoradiotherapy was performed postoperatively. Postoperative chemotherapy was performed on patients $\leq 3$ years old, both radiotherapy and chemotherapy were performed on patients $>3$ years old. 


\subsection{MR Imaging and Spectroscopy Protocol}

Brain MR images were obtained on a $3 \mathrm{~T}$ system (Philips Achieva) using an 8-channel SENSE head coil. T1-weighted spin-echo images $(\mathrm{TR} / \mathrm{TE}=700 / 300 \mathrm{~ms}$, slice thickness $=5 \mathrm{~mm}$ ); Turbo spin-echo T2-weighted images $(\mathrm{TR}=5000 \mathrm{~ms}$, TE $=100 \mathrm{~ms}$, slice thickness $=5 \mathrm{~mm}$ ); Fast fluid-attenuated inversion-recovery (FLAIR) images $(\mathrm{TR} / \mathrm{TI}=12,000 / 2850 \mathrm{~ms}, \mathrm{TE}=140 \mathrm{~ms}$, slice thickness $=5$ $\mathrm{mm}$ ); Diffusion-weighted imaging (DWI) was conducted with a single-shot spin-echo echo planar imaging sequence $(\mathrm{TR}=2653 \mathrm{~ms}, \mathrm{TE}=77 \mathrm{~ms}, \mathrm{~b}=0.1000$ $\mathrm{sec} / \mathrm{mm}^{2}$ ); Enhancement scan used Gd-DTPA for contrast agent, dose 0.1 $\mathrm{mmol} / \mathrm{kg}$, contrast-enhanced T1 spin-echo (TR/TE, 700/20 ms; slice thickness = $5 \mathrm{~mm}$ ); MRS used single voxel point resolved spectroscopy (PRESS), with TE of $35 \mathrm{~ms}$, TR of $1500 \mathrm{~ms}$. The regions of interest (ROIs) centered in the substantial parts of the tumors, excluding areas of hemorrhage, cystic, necrosis and bone.

\subsection{Image Post-Processing}

Two pediatric radiologists, who were blinded to the clinical history, histopathology, and molecular data, evaluated all MRI and MRS images. MRS analysis was processed using a automated software (the Extended MR WorkSpace 2.6.3.5 workstation manufactured by Philips company).

\subsection{Molecular Subgrouping}

Next generation sequencing (NGS) was used to detect medulloblastoma relevant 39 gene mutation, and chromosome amplification or deletion mutation to determine the molecular subtypes on the basis of gene-expression profiling, including 4 subtypes: WNT, SHH, group 3 and group 4 that combined to non $\mathrm{SHH} / \mathrm{WNT}$. Medulloblastomas harbouring somatic mutations of CTNNB1 that promote stabilization and nuclear localization of $\beta$-catenin belong to the WNT subgroup [8] [13]. WNT subgroup medulloblastomas often carry heterozygous TP53 mutations [14] [15]. Somatic mutations of PTCH1, and somatic copy number aberrations (SCNAs) affecting the SHH target genes MYCN and GLI family zinc finger 2 (GLI2), are typical of this subgroup [6] [16]. Focal high-level amplification of the MYC protooncogene is highly enriched in Group 3 medulloblastoma and almost all cases exhibit aberrant MYC expression [16] [17]. The proto-oncogenes MYCN and cyclin-dependent kinase 6 (CDK6) are recurrently amplified in Group 4 medulloblastomas [16] [17]. Formalin-fixed paraffin-embedded tissue of 24 patients and frozen tissue of 8 patients were available for molecular subgrouping.

\subsection{Statistical Analysis}

Statistical analysis was conducted using IBM's SPSS platform software (Windows, version 19.0). Patient demographics, histopathological types, prognosis, MRS and MR imaging features were compared using the $\chi^{2}$ test or Fisher exact 
test for categorical variables or independent-samples Student's $t$-test for continuous variables. $p<0.05$ was considered to be statistically significant.

\section{Results}

\subsection{Patient Demographics and Medulloblastoma Molecular Subtypes}

The patients ranged in age from 1 to 11 years with median age 6.5 years old. There were 21 male and 11 female. 22 of 32 cases were $>3$ years old, including 14 male and 8 female; 10 of 32 cases were $\leq 3$ years old, including 7 male and 3 female.

4 of 32 cases $(12.5 \%)$ were the SHH subtype, 7 of 32 cases $(21.9 \%)$ were the WNT subtype, 21 of 32 cases (65.6\%) were the non SHH/WNT subtype.

\subsection{MR Imaging Features and Molecular Subtypes}

All patients underwent MRI prior to surgical resection. There was no significant difference of tumor location, T2 and DWI signal, contrast enhancement pattern, cyst or metastatic tumor in the three molecular subtypes (Table 1, Figure 1).

16 of them underwent MRS prior to surgical resection. 2 of 16 cases (12.5\%) were the SHH subtype, 3 of 16 cases (18.8\%) were the WNT subtype, 11 of 16 cases $(68.8 \%)$ were the non SHH/WNT subtype. Metabolite concentrations were obtained by measuring area under the curve (AUC) values. $\mathrm{N}$-acetyl aspartate (NAA), choline-containing compounds (Cho), creatine ( $\mathrm{Cr}$ ), glutamate/glutamine (Glu and Gln), and lipids (Lip) of the tumor and peritumoral normal brain area were obtained and NAA/Cr, Cho/Cr, Lip/Cr, Glu and $\mathrm{Gln} / \mathrm{Cr}$ ratio were calculated with $\mathrm{Cr}$ as an internal standard.

MRS demonstrated low levels of N-acetyl aspartate (NAA), and high levels of

Table 1. MR imaging features according to medulloblastoma molecular subtypes.

\begin{tabular}{|c|c|c|c|c|c|}
\hline Variables & & $\begin{array}{c}\text { SHH, n } \\
(\%)\end{array}$ & $\begin{array}{l}\text { WNT, n } \\
(\%)\end{array}$ & $\begin{array}{c}\text { Non SHH/WNT, } \\
\text { n (\%) }\end{array}$ & $p$ \\
\hline \multirow{3}{*}{ Location } & midline/fourth ventricle & $3(75)$ & $6(85.7)$ & $18(85.7)$ & \multirow{3}{*}{0.792} \\
\hline & & & & & \\
\hline & cerebellar hemispheres & $1(25)$ & $1(14.3)$ & $3(14.3)$ & \\
\hline \multirow{3}{*}{ T2 signal } & homogeneous & $2(50)$ & $4(57.1)$ & $9(42.9)$ & \multirow{3}{*}{0.869} \\
\hline & & & & & \\
\hline & heterogeneous & $2(50)$ & $3(42.9)$ & $12(57.1)$ & \\
\hline & DWI high signal & $4(100)$ & $7(100)$ & $21(100)$ & $\mathrm{n} / \mathrm{a}$ \\
\hline & Cyst & $2(50)$ & $4(57.1)$ & $14(66.7)$ & 0.134 \\
\hline \multirow{3}{*}{$\begin{array}{c}\text { Enhancement } \\
\text { pattern }\end{array}$} & patchy & $1(25)$ & $5(71.4)$ & $17(81.0)$ & \\
\hline & homogeneous & $2(50)$ & $1(14.3)$ & $2(9.5)$ & \\
\hline & minimal or no & $1(25)$ & $1(14.3)$ & $2(9.5)$ & \\
\hline & Metastatic tumor & $0(0)$ & $2(28.6)$ & $6(28.6)$ & $\mathrm{n} / \mathrm{a}$ \\
\hline
\end{tabular}



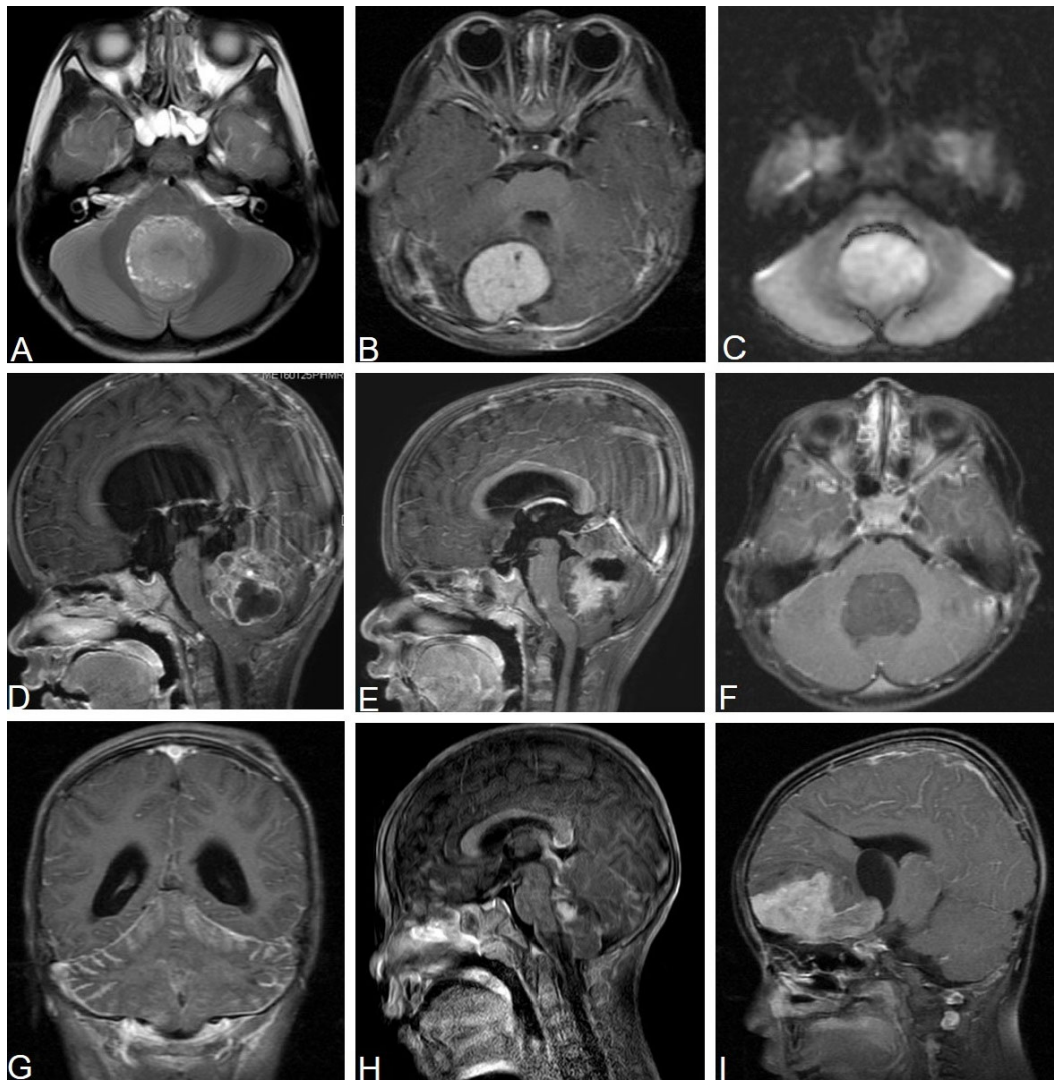

Figure 1. MR imaging features of medulloblastoma. (A) Tumor is located in the midline/fourth ventricle with heterogeneous T2 signal. (B) Tumor is located in the cerebellar hemispheres with homogeneous enhancement. (C) DWI signal of tumor is predominantly high. (D) Tumor has partially cystic. (E) Tumor shows patchy enhancement. (F) Tumor shows minimal or no enhancement. $(G)$ Tumor shows meningeal metastasis. $\mathrm{H}$ : Tumor shows meningeal metastasis and spinal cord invasion. (I), Tumor shows frontal lobe metastasis.

choline-containing compounds (Cho), with prominent or low levels of lipids (Lip) and little or no evidence of glutamate/glutamine (Glu and Gln) (Figure $2(\mathrm{~A})$ \& Figure 2(B)). The average and standard deviation of NAA/Cr ratio was $0.69 \pm 0.36(95 \% \mathrm{CI}=0.50$ to 0.88$)$; The average and standard deviation of $\mathrm{Cho} / \mathrm{Cr}$ ratio was $4.76 \pm 2.84$ ( $95 \% \mathrm{CI}=3.25$ to 6.27$)$; The average and standard deviation of $\mathrm{Lip} / \mathrm{Cr}$ ratio was $2.51 \pm 2.63$ (95\% CI $=1.11$ to 3.91 ); The average and standard deviation of Glu and $\mathrm{Gln} / \mathrm{Cr}$ ratio was $0.35 \pm 0.28(95 \% \mathrm{CI}=0.20$ to 0.50 ). We combined SHH and WNT subtype (denoted SHH+WNT) to distinguish between SHH+WNT and non SHH/WNT subtype. However, there was no significant difference of NAA/Cr $(\mathrm{t}=0.263, p=0.799)$, Cho/Cr $(\mathrm{t}=-0.509, p$ $=0.619), \mathrm{Lip} / \mathrm{Cr}(\mathrm{t}=0.506, p=0.621)$, Glu and $\mathrm{Gln} / \mathrm{Cr}$ ratio $(\mathrm{t}=1.984, p=$ 0.074 ) between SHH+WNT subtype and non SHH/WNT subtype (Figure 2(C)).

\subsection{Patient Characteristics and Molecular Subtypes}

There was no significant difference of the three molecular subtypes in age, gender and histopathological type (Table 2). 

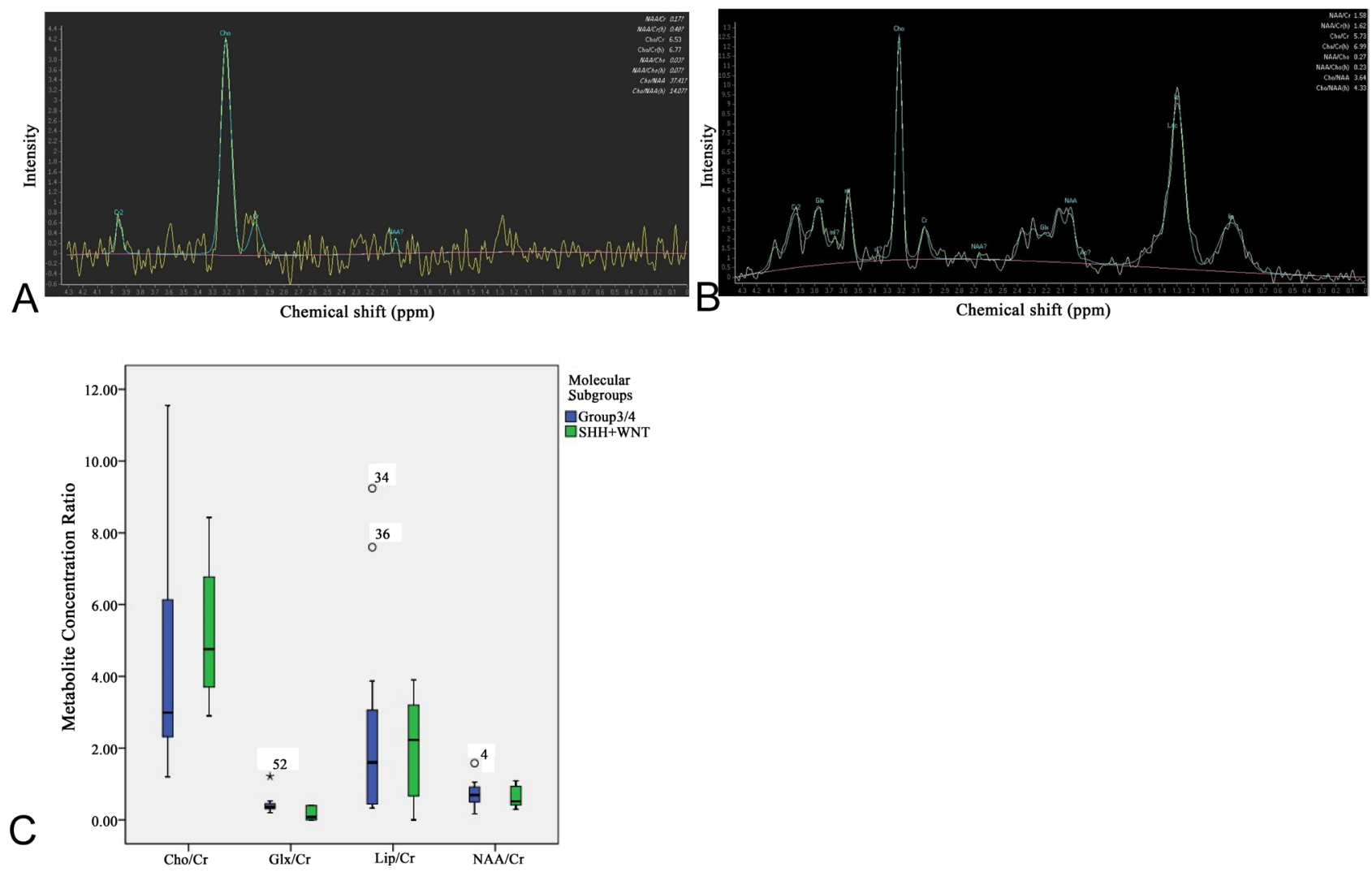

Figure 2. MRS patterns in medulloblastoma molecular subtypes. (A) A non SHH/WNT shows high level of Cho, with no evidence of NAA, Lip, Glu and Gln. (B) A non SHH/WNT tumor shows high level of Cho, low level of NAA, with prominent level of Lip and little evidence of Glu and Gln. (C) Box plots illustrating that metabolite concentration ratio among molecular subtypes of medulloblastoma.

Table 2. Patient characteristics according to medulloblastoma molecular subtypes.

\begin{tabular}{clcccc}
\hline Variables & & SHH, n (\%) & WNT, n (\%) & $\begin{array}{c}\text { Non SHH/WNT, } \\
\text { n (\%) }\end{array}$ & $p$ \\
\hline \multirow{2}{*}{ Age } & $\leq 3$ years old & $2(50)$ & $3(42.9)$ & $5(23.8)$ & 0.461 \\
& $>3$ years old & $2(50)$ & $4(57.1)$ & $16(76.2)$ & \\
\hline \multirow{2}{*}{ Sex } & male & $3(75)$ & $4(57.1)$ & $14(66.7)$ & 0.868 \\
\hline $\begin{array}{c}\text { Histopathological } \\
\text { type }\end{array}$ & female & $1(25)$ & $3(42.9)$ & $7(33.3)$ & \\
\hline
\end{tabular}

\subsection{Prognosis and Molecular Subtypes}

The 5-year event-free survival (EFS) of SHH, WNT and non SHH/WNT subtype respectively were $75 \%, 57.1 \%, 38.1 \%$, with no significant difference $(p=0.382)$. 5 -year EFS of non SHH/WNT subtype was $80 \%$ in $\leq 3$ years old group, and $25 \%$ in $>3$ years old group, with significant difference $(p=0.047)$ (Table 3$)$.

\section{Discussion}

Medulloblastoma is an invasive embryonal tumor in the posterior fossa in children. 
Table 3. Prognosis according to medulloblastoma molecular subtypes.

\begin{tabular}{ccccccc}
\hline & \multicolumn{3}{c}{$\leq 3$ years old group } & \multicolumn{3}{c}{$>$ 3 years old group } \\
\cline { 2 - 7 } & SHH & WNT & Non SHH/WNT & SHH & WNT & Non SHH/WNT \\
\hline Total cases (n) & 2 & 3 & 5 & 2 & 4 & 16 \\
Recurrence (n, \%) & 0,0 & $1,33.3$ & 1,20 & 1,50 & 2,50 & 12,75 \\
Death (n, \%) & 0,0 & $1,33.3$ & 0,0 & 0,0 & 1,25 & 8,50 \\
\hline
\end{tabular}

Extensive prognostic variability exists between individuals, 5 year overall survival ranges from $20 \%$ to $100 \%$ [2]. Several studies showed there were no differences between patient outcomes and the histopathological types (classic, desmoplastic, extensive nodularity, large cell/anaplastic) or clinical features [7] [18] [17]. In recent years, the research progress of molecular biology showed that the prognosis of medulloblastoma had a close correlation with molecular subtypes [6] [19]. Each subgroup exhibits distinct molecular genetic and metabolic profiles that would facilitate specific targeted therapy [20] [21] [22]. Group 3 and group 4 have different metabolic profiles as compared with WNT and SHH subtypes, due to the frequent MYC or MYCN oncogene amplification and overexpression in the former subtypes [7] [18].

MRS has great significance in the differential diagnosis of brain tumors and predicting the clinical outcomes, which determines in vivo concentrations of metabolites of the tumors [23] [24]. As widely known no single tumor feature could be used alone to identify tumor subtype [25], MRS can offer additional options. High total $\mathrm{Cho} / \mathrm{Cr}$ ratios and low total NAA/Cr ratios have been noted as biomarkers of poor prognosis for plenty of tumours [26] [27] [28]. Peet AC et al. [12] reported higher levels of total choline and lower levels of mobile lipids were observed in patients with metastatic medulloblastoma. Martin et al. [29] found glutamate detected by MRS could predict survival in pediatric medulloblastoma.

In our study, we acquired metabolites measured by MRS and MR imaging features of patients with medulloblastoma, to investigate their prediction of molecular subtypes of pediatric medulloblastoma. Although Blüml S et al. [11] and Perreault $S$ et al. [30] reported MRS and MRI as non-invasive and accurate tools to differentiate molecular subtypes of medulloblastoma, in this study we indeed found MRS and MR imaging features differed from different individuals, but without statistic significance to be used to determine molecular subtypes. This result may be influenced by the small sample size of our study, and need to be repeated on a larger scale and confirmed in a validation cohort.

Survival outcomes differ based on molecular subtypes, with good survival observed in children with WNT subtype and intermediate survival prospect in infants with SHH subtype [6] [18] [31]. In contrast, patients of group 3 and group 4 have a poor prognosis [18] [32]. Previous study has reported that almost 75\% patients with medulloblastoma relapsed in the first 2 years postoperation [33]. In the current study, molecular subgrouping analysis revealed that more than a half 
of the children were the non SHH/WNT subtype, with 5-year EFS of $38.1 \%$, which is poorer than $\mathrm{SHH}$ of $75 \%$ and WNT of $57.1 \%$. However there was no statistic significant difference that may due to the study sample size. 5-year EFS of non SHH/WNT subtype in $\leq 3$ years old group was $80 \%$, compared to $25 \%$ in $>3$ years old group, which was significantly higher $(p=0.047)$. Differ from previous studies which reported $\leq 3$ years old as an independent risk factor of medulloblastoma [34] [35], our result may be related to the follow-up period.

In conclusion, MRS and MR imaging features can't be used to determine molecular subtypes of medulloblastoma based on our small sample study. There was no significant difference of the prognosis in the three molecular subtypes. The prognosis of $\leq 3$ years old group of non SHH/WNT subtype is better than $>$ 3 years old group.

\section{Acknowledgements}

The authors would like to thank Dr. Jin Zhu (Department of Pathology, Children's Hospital of Chongqing Medical University), for his contributions to this work.

\section{Funding}

The project was funded by General project of Chongqing Science and Technology Commission (cstc2019jscx-msxmX0143).

\section{Conflicts of Interest}

The authors declare no conflicts of interest regarding the publication of this paper.

\section{References}

[1] Poretti, A., Meoded, A. and Huisman, T.A. (2012) Neuroimaging of Pediatric Posterior Fossa Tumors Including Review of the Literature. Journal of Magnetic Resonance Imaging, 35, 32-47. https://doi.org/10.1002/jmri.22722

[2] Gerber, N.U., Mynarek, M., von Hoff, K., Friedrich, C., Resch, A. and Rutkowski, S. (2014) Recent Developments and Current Concepts in Medulloblastoma. Cancer Treatment Reviews, 40, 356-365. https://doi.org/10.1016/j.ctrv.2013.11.010

[3] Louis, D.N., Ohgaki, H., Wiestler, O.D., Cavenee, W.K., Burger, P.C., Jouvet, A., Scheithauer, B.W. and Kleihues, P. (2007) The 2007 WHO Classification of Tumours of the Central Nervous System. Acta Neuropathologica, 114, 97-109. https://doi.org/10.1007/s00401-007-0243-4

[4] Ellison, D.W., Onilude, O.E., Lindsey, J.C., Lusher, M.E., Weston, C.L., Taylor, R.E., Pearson, A.D. and Clifford, S.C. (2005) United Kingdom Children's Cancer Study Group Brain Tumour Committee. Beta-Catenin Status Predicts a Favorable Outcome in Childhood Medulloblastoma: The United Kingdom Children's Cancer Study Group Brain Tumour Committee. Journal of Clinical Oncology, 23, 7951-7957. https://doi.org/10.1200/JCO.2005.01.5479

[5] Gajjar, A., Chintagumpala, M., Ashley, D., Kellie, S., Kun, L.E., Merchant, T.E., Woo, S., Wheeler, G., Ahern, V., Krasin, M.J., Fouladi, M., Broniscer, A., Krance, 
R., Hale, G.A., Stewart, C.F., Dauser, R., Sanford, R.A., Fuller, C., Lau, C., Boyett, J.M., Wallace, D. and Gilbertson, R.J. (2006) Risk-Adapted Craniospinal Radiotherapy Followed by High-Dose Chemotherapy and Stem-Cell Rescue in Children with Newly Diagnosed Medulloblastoma (St Jude Medulloblastoma-96): Long-Term Results From a Prospective, Multicentre Trial. The Lancet Oncology, 7, 813-820. https://doi.org/10.1016/S1470-2045(06)70867-1

[6] Kool, M., Korshunov, A., Remke, M., Jones, D.T., Schlanstein, M., Northcott, P.A., Cho, Y.J., Koster, J., Schouten-van Meeteren, A., van Vuurden, D., Clifford, S.C., Pietsch, T., von Bueren, A.O., Rutkowski, S., McCabe, M., Collins, V.P., Bäcklund, M.L., Haberler, C., Bourdeaut, F., Delattre, O., Doz, F., Ellison, D.W., Gilbertson, R.J., Pomeroy, S.L., Taylor, M.D., Lichter, P. and Pfister, S.M. (2012) Molecular Subgroups of Medulloblastoma: An International Meta-Analysis of Transcriptome, Genetic Aberrations, and Clinical Data of WNT, SHH, Group 3, and Group $4 \mathrm{Me}-$ dulloblastomas. Acta Neuropathologica, 123, 473-484. https://doi.org/10.1007/s00401-012-0958-8

[7] Northcott, P.A., Korshunov, A., Witt, H., Hielscher, T., Eberhart, C.G., Mack, S., Bouffet, E., Clifford, S.C., Hawkins, C.E., French, P., Rutka, J.T., Pfister, S. and Taylor, M.D. (2011) Medulloblastoma Comprises Four Distinct Molecular Variants. Journal of Clinical Oncology, 29, 1408-1414. https://doi.org/10.1200/JCO.2009.27.4324

[8] Thompson, M.C., Fuller, C., Hogg, T.L., Dalton, J., Finkelstein, D., Lau, C.C., Chintagumpala, M., Adesina, A., Ashley, D.M., Kellie, S.J., Taylor, M.D., Curran, T., Gajjar, A. and Gilbertson, R.J. (2006) Genomics Identifies Medulloblastoma Subgroups That Are Enriched for Specific Genetic Alterations. Journal of Clinical Oncology, 24, 1924-1931. https://doi.org/10.1200/JCO.2005.04.4974

[9] Toyooka, M., Kimura, H., Uematsu, H., Kawamura, Y., Takeuchi, H. and Itoh, H. (2008) Tissue Characterization of Glioma by Proton Magnetic Resonance Spectroscopy and Perfusion-Weighted Magnetic Resonance Imaging: Glioma Grading and Histological Correlation. Clinical Imaging, 32, 251-258.

https://doi.org/10.1016/j.clinimag.2007.12.006

[10] Fayed, N., Dávila, J., Medrano, J. and Olmos, S. (2008) Malignancy Assessment of Brain Tumours with Magnetic Resonance Spectroscopy and Dynamic Susceptibility Contrast MRI. European Journal of Radiology, 67, 427-433. https://doi.org/10.1016/j.ejrad.2008.02.039

[11] Blüml, S., Margol, A.S., Sposto, R., Kennedy, R.J., Robison, N,J., Vali, M., Hung, L.T., Muthugounder, S., Finlay, J.L., Erdreich-Epstein, A., Gilles, F.H., Judkins, A.R., Krieger, M.D., Dhall, G., Nelson, M.D. and Asgharzadeh, S. (2016) Molecular Subgroups of Medulloblastoma Identification Using Noninvasive Magnetic Resonance Spectroscopy. Neuro-Oncology, 18, 126-131. https://doi.org/10.1093/neuonc/nov097

[12] Peet, A.C., Davies, N.P., Ridley, L., Brundler, M.A., Kombogiorgas, D., Lateef, S., Natarajan, K., Sgouros, S., MacPherson, L. and Grundy, R.G. (2007) Magnetic Resonance Spectroscopy Suggests Key Differences in the Metastatic Behaviour of Medulloblastoma. European Journal of Cancer, 43, 1037-1044.

https://doi.org/10.1016/j.ejca.2007.01.019

[13] Clifford, S.C., et al. (2006) Wnt/Wingless Pathway Activation and Chromosome 6 Loss Characterize a Distinct Molecular Sub-Group of Medulloblastomas Associated with a Favorable Prognosis. Cell Cycle, 5, 2666-2670.

https://doi.org/10.4161/cc.5.22.3446

[14] Pfaff, E., et al. (2010) TP53 Mutation Is Frequently Associated with CTNNB1 Mutation or MYCN Amplification and Is Compatible with Long-Term Survival in Medulloblastoma. Journal of Clinical Oncology, 28, 5188-5196. 
https://doi.org/10.1200//CO.2010.31.1670

[15] Lindsey, J.C., et al. (2011) TP53 Mutations in Favorable-Risk Wnt/Wingless-Subtype Medulloblastomas. Journal of Clinical Oncology, 29, e344-e346. https://doi.org/10.1200/JCO.2010.33.8590

[16] Northcott, P.A., et al. (2011) Medulloblastoma Comprises Four Distinct Molecular Variants. Journal of Clinical Oncology, 29, 1408-1414. https://doi.org/10.1200/JCO.2009.27.4324

[17] Cho, Y.J., et al. (2011) Integrative Genomic Analysis of Medulloblastoma Identifies a Molecular Subgroup That Drives Poor Clinical Outcome. Journal of Clinical Oncology, 29, 1424-1430. https://doi.org/10.1200/JCO.2010.28.5148

[18] Taylor, M.D., Northcott, P.A., Korshunov, A., Remke, M., Cho, Y.J., Clifford, S.C., Eberhart, C.G., Parsons, D.W., Rutkowski, S., Gajjar, A., Ellison, D.W., Lichter, P., Gilbertson, R.J., Pomeroy, S.L., Kool, M. and Pfister, S.M. (2012) Molecular Subgroups of Medulloblastoma: The Current Consensus. Acta Neuropathologica, 123, 465-472. https://doi.org/10.1007/s00401-011-0922-Z

[19] Ellison, D.W., Kocak, M., Dalton, J., Megahed, H., Lusher, M.E., Ryan, S.L., Zhao, W., Nicholson, S.L., Taylor, R.E., Bailey, S. and Clifford, S.C. (2011) Definition of Disease-Risk Stratification Groups in Childhood Medulloblastoma Using Combined Clinical, Pathologic, and Molecular Variables. Journal of Clinical Oncology, 29, 1400-1407. https://doi.org/10.1200/JCO.2010.30.2810

[20] Rodriguez-Blanco, J., Pednekar, L., Penas, C., Li, B., Martin, V., Long, J., Lee, E., Weiss, W.A., Rodriguez, C., Mehrdad, N., Nguyen, D.M., Ayad, N.G., Rai, P., Capobianco, A.J. and Robbins, D.J. (2017) Inhibition of WNT Signaling Attenuates Self-Renewal of SHH-Subgroup Medulloblastoma. Oncogene, 36, 6306-6314. https://doi.org/10.1038/onc.2017.232

[21] Dennis, M., Spiegler, B.J., Hetherington, C.R. and Greenberg, M.L. (1996) Neuropsychological Sequelae of the Treatment of Children with Medulloblastoma. Journal of Neuro-Oncology, 29, 91-101. https://doi.org/10.1007/BF00165522

[22] Yuneva, M.O., Fan, T.W., Allen, T.D., Higashi, R.M., Ferraris, D.V., Tsukamoto, T., Matés, J.M., Alonso, F.J., Wang, C., Seo, Y., Chen, X. and Bishop, J.M. (2012) The Metabolic Profile of Tumors Depends on Both the Responsible Genetic Lesion and Tissue Type. Cell Metabolism, 15, 157-170. https://doi.org/10.1016/j.cmet.2011.12.015

[23] Wilson, M., Cummins, C.L., Macpherson, L., Sun, Y., Natarajan, K., Grundy, R.G., Arvanitis, T.N., Kauppinen, R.A. and Peet, A.C. (2013) Magnetic Resonance Spectroscopy Metabolite Profiles Predict Survival in Paediatric Brain Tumours. European Journal of Cancer, 49, 457-464. https://doi.org/10.1016/j.ejca.2012.09.002

[24] Marcus, K.J., Astrakas, L.G., Zurakowski, D, Zarifi, M.K., Mintzopoulos, D., Poussaint, T.Y., Anthony, D.C., De Girolami, U., Black, P.M., Tarbell, N.J. and Tzika, A.A. (2007) Predicting Survival of Children with CNS Tumors Using Proton Magnetic Resonance Spectroscopic Imaging Biomarkers. International Journal of Oncology, 30, 651-657. https://doi.org/10.3892/ijo.30.3.651

[25] Robinson, G.W. (2013) Impact of Tumor Location on Medulloblastoma Subtyping and Treatment. Pediatric Blood \& Cancer, 60, 1393-1394.

https://doi.org/10.1002/pbc.24549

[26] Astrakas, L.G., Zurakowski, D., Tzika, A.A., Zarifi, M.K., Anthony, D.C., De Girolami, U., Tarbell, N.J. and Black, P.M. (2004) Noninvasive Magnetic Resonance Spectroscopic Imaging Biomarkers to Predict The Clinical Grade of Pediatric Brain Tumors. Clinical Cancer Research, 10, 8220-8228. 
https://doi.org/10.1158/1078-0432.CCR-04-0603

[27] Li, X., Jin, H., Lu, Y., Oh, J., Chang, S. and Nelson, S.J. (2004) Identification of MRI and $1 \mathrm{H}$ MRSI Parameters That May Predict Survival for Patients with Malignant Gliomas. NMR Biomedicine, 17, 10-20. https://doi.org/10.1002/nbm.858

[28] Vaidya, S.J., Payne, G.S., Leach, M.O. and Pinkerton, C.R. (2003) Potential Role of Magnetic Resonance Spectroscopy in Assessment of Tumour Response in Childhood Cancer. European Journal of Cancer, 39, 728-735. https://doi.org/10.1016/S0959-8049(02)00728-1

[29] Wilson, M., Gill, S.K., MacPherson, L., English, M., Arvanitis, T.N. and Peet, A.C. (2014) Noninvasive Detection of Glutamate Predicts Survival in Pediatric Medulloblastoma. Clinical Cancer Research, 20, 4532-4539. https://doi.org/10.1158/1078-0432.CCR-13-2320

[30] Perreault, S., Ramaswamy, V., Achrol, A.S., Chao, K., Liu, T.T., Shih, D., Remke, M., Schubert, S., Bouffet, E., Fisher, P.G., Partap, S., Vogel, H., Taylor, M.D., Cho, Y.J. and Yeom, K.W. (2014) MRI Surrogates for Molecular Subgroups of Medulloblastoma. American Journal of Neuroradiology, 35, 1263-1269. https://doi.org/10.3174/ajnr.A3990

[31] Pietsch, T., Schmidt, R., Remke, M., Korshunov, A., Hovestadt, V., Jones, D.T., Felsberg, J., Kaulich, K., Goschzik, T., Kool, M., Northcott, P.A., von Hoff, K., von Bueren, A.O., Friedrich, C., Mynarek, M., Skladny, H., Fleischhack, G., Taylor, M.D., Cremer, F., Lichter, P., Faldum, A., Reifenberger, G., Rutkowski, S. and Pfister, S.M. (2014) Prognostic Significance of Clinical, Histopathological, and Molecular Characteristics of Medulloblastomas in the Prospective Hit2000 Multicenter Clinical Trial Cohort. Acta Neuropathologica, 128, 137-149. https://doi.org/10.1007/s00401-014-1276-0

[32] Pfister, S., Remke, M., Benner, A., Mendrzyk, F., Toedt, G., Felsberg, J., Wittmann, A., Devens, F., Gerber, N.U., Joos, S., Kulozik, A., Reifenberger, G., Rutkowski, S., Wiestler, O.D., Radlwimmer, B., Scheurlen, W., Lichter, P. and Korshunov, A. (2009) Outcome Prediction in Pediatric Medulloblastoma Based on DNA Copy-Number Aberrations of Chromosomes $6 \mathrm{q}$ and $17 \mathrm{q}$ and the MYC and MYCN Loci. Journal of Clinical Oncology, 27, 1627-1636. https://doi.org/10.1200/JCO.2008.17.9432

[33] Rossi, A., Caracciolo, V., Russo, G., Reiss, K. and Giordano, A. (2008) Medulloblastoma: from Molecular Pathology to Therapy. Clinical Cancer Research, 14, 971-976. https://doi.org/10.1158/1078-0432.CCR-07-2072

[34] Massimino, M., Biassoni, V., Gandola, L., Garrè, M.L., Gatta, G., Giangaspero, F., Poggi, G. and Rutkowski, S. (2016) Childhood Medulloblastoma. Critical Reviews in Oncology/Hematology, 105, 35-51. https://doi.org/10.1016/j.critrevonc.2016.05.012

[35] Remke, M., Hielscher, T., Northcott, P.A., Witt, H., Ryzhova, M., Wittmann, A., Benner, A., von Deimling, A., Scheurlen, W., Perry, A., Croul, S., Kulozik, A.E., Lichter, P., Taylor, M.D., Pfister, S.M. and Korshunov, A. (2011) Adult Medulloblastoma Comprises Three Major Molecular Variants. Journal of Clinical Oncology, 29, 2717-2723. https://doi.org/10.1200/JCO.2011.34.9373 